\title{
Tradução, língua alemã e pós-graduação: três relatos, uma diretriz
}

\author{
Magdalena Nowinska* \\ Cristiana Oliveira \\ Emiliano Rossi
}

\begin{abstract}
This article presents some examples of translation research in German Studies, on postgraduate level (master's degree program). Following a tradition of the University of São Paulo, going back to the 1960s, such master's dissertations aim at presenting translations of texts yet unpublished in Brazil. Accompanied by annotations and commentaries, the translations are anchored in theoretical perspectives of Translation Studies. The three reports presented here concede a look behind the scenes of research in translation, which includes detailed analyses of the texts to be translated, and which is directed and enlarged by theoretical readings accompanying the actual translation phase. The latter, conducted in various stages, focuses on specific problems of the different levels of linguistic - and, if necessary, literary - analyses, thus influencing the composition of the annotations and commentaries, as well as the subsequent attempts at "re-writing" the text in translation. At the end of the process, annotations and commentaries are selected and related to a chosen theoretical perspective, and it is only then that the final version of the dissertation is composed, its argumentation following the direction of a reflection based on the translation practice.
\end{abstract}

Keywords: translation research; German-Portuguese translation.

Resumo: O presente artigo tem por objetivo apresentar uma amostra de pesquisas com a língua alemã nos trabalhos de grau da pós-graduação (nível de mestrado) envolvendo a tradução. Seguindo uma tradição que, na Universidade de São Paulo, remonta aos anos de 1960, tais trabalhos têm por objetivo apresentar a tradução de textos inéditos, acompanhados de notas e comentários, e - ao contrário dos trabalhos realizados àquela época - são ancorados numa perspectiva teórica dos Estudos da Tradução (Translation Studies na nomenclatura internacional). A partir de três relatos de pesquisas em andamento, procura-se revelar os bastidores do trabalho com os textos, bem como a fase de análise do texto a ser traduzido, que é pautada e aprofundada por leituras teóricas e realizada paralela e concomitantemente à fase de tradução propriamente dita. Esta última, empreendida em várias etapas, enfoca a cada vez uma dificuldade específica dos diferentes níveis da análise lingüística - e, dependendo do caso, também literária - e sugere a redação de notas, comentários e diferentes tentativas de reescritura. Ao final do processo, as notas e comentários são selecionados e relacionados com a perspectiva teórica, para que só então se processe a redação final da Dissertação, cuja diretriz é construída numa direção que vai da prática de traduzir para a reflexão.

Palavras-chave: pesquisa em tradução; língua alemã.

\footnotetext{
* Mestrandos do Programa de Pós-Graduação em Língua e Literatura Alemã, da Universidade de São Paulo, sob orientação do Prof. Dr. João Azenha Junior. mnowinska@gmx.net; rossiemiliano@yahoo.com.br; kikaberea@hotmail.com.
} 
Zusammenfassung: Dieser Sammelaufsatz stellt eine Auswahl germanistischer Forschungsprojekte vor, die in Master-Studiengängen im Bereich Übersetzung durchgeführt werden. Im Sinne einer Tradition, die an der Universität São Paulo seit den 60er Jahren besteht, setzen sich solche Arbeiten zum Ziel, Übersetzungen von in Brasilien noch nicht veröffentlichten Texten vorzulegen, die von Anmerkungen und Kommentaren begleitet und zudem - im Gegensatz zu den früheren Arbeiten - in theoretischen Ansätzen aus dem Bereich der Translation Studies verankert sind. Ausgehend von drei Berichten aus laufenden Forschungen sollen hier die Kulissen der Arbeit am Text, sowie einzelne Phasen der Textanalyse verdeutlicht werden, die, durch theoretische Lektüren abgesteckt und vertieft, parallel und begleitend zur eigentlichen Übersetzungsphase stattfinden. Letztere konzentriert sich, in unterschiedlichen Etappen, auf spezifische Probleme der verschiedenen Ebenen der sprachlichen - und unter Umständen auch literarischen Analyse, aus der Anmerkungen und Kommentare, sowie verschiedene "Neuschreibungen" der Texte hervorgehen. Zum Abschluss dieses Vorgangs werden Anmerkungen und Kommentare ausgewählt und theoretisch verortet, um erst an dieser Stelle in der endgültigen Fassung der Dissertation zusammengestellt zu werden, deren Richtlinien somit aus der Praxis des Übersetzens heraus und hin zur abstrakteren Reflexion konstruiert werden.

Stichwörter: Übersetzungsforschung; deutsche Sprache/Germanistik.

\section{Introdução}

Trabalhos de grau envolvendo a tradução, seja em nível de mestrado, seja no de doutorado, são uma forte tradição na produção intelectual de docentes e discentes da Faculdade de Filosofia, Letras e Ciências Humanas (FFLCH) da Universidade de São Paulo há pelo menos cinco décadas. Nos anos de 1960 e 1970, antes mesmo de se concentrarem fundamentalmente na Faculdade de Letras - o que passa a ocorrer a partir de meados da década de 1970 -, as teses e dissertações envolvendo a tradução encontram-se dispersas por áreas como Filosofia, História, Sociologia, Antropologia, Lingüística, Teoria Literária e também, mas em escala menor, nas Letras (cf. CATÁLOGO ${ }^{1}$, 1998).

Um breve exame da produção intelectual desse período (cf. AZENHA 2007) revela a constituição de, basicamente, três eixos, a partir dos quais se têm estruturado desde então os Estudos da Tradução nessa Instituição: (1) trabalhos contrastivos nos diferentes níveis da análise lingüística, (2) trabalhos de literatura comparada e (3) trabalhos que se referem ao ensino de línguas e literaturas estrangeiras.

\footnotetext{
${ }^{1}$ A indicação "Catálogo" diz respeito ao Catálogo de Teses e Dissertaçôes 1942-1997 organizado pela Comissão de Pós-Graduação da FFLCH-USP em 1998 (cf. Referências Bibliográficas).
} 
Nessa linha de tradição, os trabalhos envolvendo a tradução no interior do Programa de Pós-Graduação em Língua e Literatura Alemã têm incorporado, através de um diálogo profícuo, não apenas os avanços obtidos pelos Estudos da Tradução no Brasil e também no exterior, mas também as conquistas de áreas de estudo correlatas, das quais se destacam - no plano da Lingǘstica - os estudos contrastivos alemão-português e - no plano da Literatura - os projetos de pesquisa inseridos na linha de pesquisa "Germanística Intercultural". Nesse sentido, e diferentemente do que ocorria nas décadas de 1960 e 1970, esses trabalhos mantêm sua vocação de trazer a público a tradução comentada e anotada para o português do Brasil de obra inédita da literatura alemã ou, no caso de textos técnicos e científicos, de áreas específicas do saber, mas acrescentam a essa vocação a preocupação pela objetividade, entendida aqui não como a aspiração pelo cientificismo - marca de algumas tendências dos Estudos da Tradução das décadas de $1950 \mathrm{a}$ 1970 -, mas como o propósito de desvestir o trabalho de tradução de uma base meramente intuitiva e de revelar passo a passo as etapas desse complexo processo de tomada de decisões, que só ganha uma unidade na relação consciente e coerente entre teoria e prática.

Os relatos que se seguem, todos eles relatos de pesquisas em andamento $^{2}$, têm em comum esse propósito. A despeito de seus diferentes objetos de pesquisa e, conseqüentemente, de seus corpora diversificados, tais relatos permitem ao leitor acompanhar, ao menos em parte, as reflexões que norteiam esse tipo específico de trabalho em tradução em nível de pósgraduação e suas articulações com áreas de saber correlatas. Além disso, e considerando-se sua natureza como obra aberta, experimental, esses trabalhos relêem a tradição a partir de uma perspectiva atual, ao mesmo tempo em que testam os limites da criatividade do tradutor-pesquisador, preocupado em vencer, através da tradução, um hiato cultural, temporal e espacial muitas vezes desafiador.

\footnotetext{
2 Os relatos aqui reunidos fizeram parte de um painel intitulado "Metodologias da pesquisa com a língua alemã em trabalhos de tradução na pós-graduação" e foram apresentados na III Jornada de Língua Alemã, realizada de 7 a 11 de maio de 2007 na FFLCH - USP.
} 


\section{Primeiro relato}

\section{A tradução de Die Judenbuche de Annette von Droste-Hülshoff: apresentação de um trabalho em progresso.}

Por Magdalena Nowinska.

Este breve relato tem como objetivo suscitar algumas reflexões acerca de estratégias de pesquisa em tradução. Partindo-se de um problema concreto na tradução de uma novela alemã do século XIX, pretendo discutir algumas das propostas da teoria do skopos. Nesse sentido, não pretendo aqui apresentar uma solução final para os problemas mencionados, mas simplesmente discutir possíveis estratégias à luz de uma determinada teoria da tradução.

Os exemplos discutidos a seguir advêm de um projeto de mestrado em tradução. Esse projeto visa, de um lado, a apresentar uma tradução para o português da novela Die Judenbuche (A faia dos judeus), de 1842, de autoria de Annette von Droste-Hülshoff. Como um trabalho de pesquisa, porém, esse projeto pretende também refletir sobre procedimentos de tradução em relação a teorias da tradução, na tentativa de identificar problemas e caminhos para a tradução pretendida. A discussão que se segue é resultado dessa estratégia. Partindo da reflexão acerca de um problema concreto na tradução de Die Judenbuche - a tradução do vocabulário histórico dentro do texto literário, ligado a instituições sociais da realidade alemã do século XVIII, presentes no "mundo textual" ("text-world", cf. NORD 1997:87) da novela - pretendo mostrar, neste artigo, possíveis estratégias de tradução com base em algumas propostas da teoria do skopos.

Após uma breve reflexão sobre as propostas da teoria do skopos, serão apresentados os termos alemães e suas possíveis traduções, seguidos, por sua vez, de uma espécie de oficina de tradução na qual pretendo refletir sobre a relação entre os problemas e o modelo teórico escolhido para a discussão, cogitando algumas possíveis estratégias para as necessárias escolhas de tradução.

A teoria do skopos considera a tradução um processo, uma ação no sentido de uma interação intercultural, intencional, interpessoal, parcialmente verbal e baseada em um texto de origem (cf. NORD 1997:18). Partindo desse pressuposto, a teoria do skopos sugere alguns possíveis modelos de tradução, para textos literários tanto quanto para textos técnicos, e baseados em diferentes objetivos (ou skopos), os quais uma tradução supostamente pode ter. 
NoRD (1997) organiza esses modelos em dois tipos superiores, o da tradução documental e o da tradução instrumental, subdivididos, por sua vez, em vários subtipos (cf. NORD 1997:45-52). O modelo de tradução que proponho testar nesta discussão é o da tradução filológica, uma sub-espécie do gênero da tradução documental e, ao meu ver, na tipologia da teoria do skopos, o mais adequado para os objetivos de uma tradução comentada e anotada de um texto literário, que proponho fazer para Die Judenbuche.

A tradução filológica é definida como uma tradução que "[...] reproduces the source text rather literally but adds the necessary explanations about the source culture or some peculiarities of the source language in footnotes and glossaries [...]" (NORD 1997:49). Essa definição não é entendida como uma regra fixa para este tipo de traduções, já que a própria teoria do skopos se entende como uma teoria geral, que pretende estimular reflexões acerca da tradução e não estabelecer normas ou regras translatoriais (cf. NORD 1997:118). É nesse sentido, contudo, que considero pertinentes questões acerca de alguns pontos vagos dessa definição. Por ser uma definição genérica, ela deixa em aberto vários aspectos, que ficam visíveis no percorrer do processo de traduzir um texto: quão "literal" seria uma tradução feita "rather literally"? Quais ou que tipo de explicações seriam consideradas necessárias ("necessary") para uma tradução filológica? Que tipo de peculiaridades ("peculiarities") de um idioma deveria ser inserido nas notas de rodapé ou em glossários?

Cada tradução literária é, a meu ver, um processo individual, baseado em um texto singular. Portanto, cabe ao tradutor definir individualmente esses pontos vagos para cada tradução. A seguir, tentarei deixar claras as estratégias que aplico à tradução de Die Judenbuche. A discussão concentra-se em um personagem da novela, o Gutsherr, que, por apresentar interessantes interferências interculturais para essa tradução, parece-me um objeto interessante de análise.

A trama de Judenbuche acontece numa comunidade rural e gira em torno de um protagonista, Friedrich Mergel. Outro personagem da narrativa é um nobre que assume os papéis de investigador e de juiz em dois casos criminais. No âmbito do texto, encontram-se quatro diferentes referências a esse segundo personagem: ele é denominado principalmente de Gutsherr, mas também de Gutsbesitzer, Baron e Herr von S. Gutsbesitzer, que é usado uma só vez, no início da narrativa (DROSTE-HüLSHOFF 1999:10), e não remete ao personagem como um indivíduo, mas à aristocracia rural, à qual o Gutsherr 
pertence. A primeira referência ao personagem como indivíduo é feita por meio do termo Gutsherr (Droste-HÜLSHOFF 1999:36). Baron e Herr von S. são acrescentados no decorrer da narrativa e são usados sem aparente diferenciação ou preferência por um dos termos. Talvez a variação de denominações tenha razões estéticas (um desejo de evitar repetições) e/ou seja uma estratégia narrativa de individualização do personagem que, exclusivamente como Gutsherr, seria talvez estereotipado demais.

Com a exceção de Herr, nenhum desses termos é de uso corrente na língua alemã contemporânea. O título Baron, tanto quanto a preposição von no nome do personagem, caracterizam-no como um membro da nobreza. A própria narrativa permite algumas conclusões adicionais sobre esse personagem. No contexto da narrativa, fica claro que ele é uma autoridade local que tem poder policial - ele conduz a investigação nos casos criminais, incluindo uma busca na casa do suspeito, e comanda homens que assumem o papel de policiais - e também poder judiciário: ele é o juiz nos dois casos criminais. Uma pesquisa dos termos Gutsherr e Gutsbesitzer em dicionários monolíngües revela outros aspectos: segundo o Duden Universalwörterbuch, um Gutsbesitzer é um proprietário ou grande proprietário de terras agrícolas (DUDEN 2006). O mesmo dicionário define Gutsherr como "proprietário de terra e chefe daqueles que trabalham na sua propriedade" (DuDEN 2006).

Temos aqui, então, um nobre, proprietário de terras, que aparentemente tem também algum poder político na comunidade. Na hora de procurar traduções dos quatro termos, o título de Baron não apresenta grandes dificuldades, já que o mesmo título de nobreza, barão, existe em português. Para a expressão Herr von S. propõem-se duas alternativas: senhor e Dom. Senhor é uma expressão mais genérica e, nesse sentido, corresponde mais ao alemão Herr, sendo que tanto Herr quanto senhor podem ser usados como uma forma respeitosa de tratamento dispensada a homens e como a designação de uma pessoa de importância, e esses são os usos da expressão Herr von S. na Judenbuche. A expressão Dom soa mais familiar como forma de tratamento para membros de nobreza; mas a definição como "título honorífico que precede o nome de batismo, aplicado a monarcas e príncipes ou a membros da alta nobreza de Portugal e Espanha" e "entre espanhóis e hispano-americanos, título que precede o nome de batismo, aplicado a qualquer homem adulto a quem se quer tratar com cortesia, deferência ou respeito" (HouAISS 2002) liga o termo talvez um pouco demais às regiões ibéricas (cf. discussão abaixo). 
As duas outras expressões, Gutsbesitz̧er e Gutsherr, ${ }^{3}$ designações ligadas, como já mencionei, à propriedade rural, são traduzidas pelos dois dicionários bilíngües consultados, Langenscheidts Taschenwörterbuch e o Dicionário de alemão português da Porto Editora, como proprietário, proprietário rural, fazendeiro e latifundiário (LANGENSCHEIDT 2001 e PORTO 1986). ${ }^{4}$ Discutirei esses termos adiante, mas gostaria aqui de chamar a atenção para o fato de que todas essas expressões portuguesas se referem exclusivamente aos aspectos sócioeconômico e jurídico dos dois termos alemães, ou seja, todas elas definem Gutsherr e Gutsbesitzer somente como agricultor e/ou proprietário de terra. Contudo, no contexto da história, como já mencionei, a atividade do personagem não se limita somente a esse aspecto, já que ele desempenha também papéis políticos na região. Ao que parece, ele é o "chefe" da região. É ele que é autorizado a impor a ordem e sua autoridade é reconhecida pelos moradores da comunidade. Sendo assim, um termo como o do coronel - no sentido do coronelismo brasileiro - definido como um "indivíduo, geralmente proprietário rural, ocasionalmente um burocrata, comerciante ou profissional liberal do interior do país, que controla o poder político, social e econômico da região" (HOUAISs 2002), pareceria, à primeira vista, mais adequado como tradução. Seria, contudo, justificado usar esse tipo de termo para o contexto dessa narrativa? Será que o coronelismo como um fenômeno político da cultura brasileira é compatível com a realidade apresentada em Judenbuche?

A trama da narrativa, publicada em 1842, pode ser localizada no tempo e espaço por meio de indicadores no texto. As localidades concretas são mantidas anônimas - o lugar principal da trama é um vilarejo chamado simplesmente de B. - mas o texto localiza esse vilarejo na Alemanha, e o subtítulo da novela, "um quadro de costumes da Vestfália serrana", limita ainda mais a região ao noroeste da Alemanha, a Vestfália, região onde a autora viveu e onde houve, na época dela, um caso de assassinato que serviu de base para a narração fictícia de Judenbuche. O texto é também bastante específico quanto ao período da trama, que começa em 1738, com o nascimento do protagonista, e termina em $1788 .^{5}$

Trata-se aqui, então, de uma história em uma região rural da Alemanha, no século XVIII e a novela faz questão de localizar a trama nesse tempo e

\footnotetext{
3 Nesta discussão, os dois termos são tratados conjuntamente porque representam a mesma função social. 4 Ambos os dicionários propõem também o termo "lavrador", que eu, no entanto, descartei para esta discussão, por referir-se mais ao trabalho rural do que à propriedade.

$5 \mathrm{O}$ texto da novela informa o ano 1788; pela seqüência da trama o ano final deveria ser, porém, 1789. Esse "erro" da autora foi discutido amplamente por vários autores - cf., entre outros, TYTLER (2000:347) e HUGE (2006:23-25) - mas ele não tem importância para os fins desta discussão, que somente procura delimitar aproximadamente um período de tempo.
} 
espaço. ${ }^{6}$ Essa época não era muito remota ao tempo da publicação da novela; a autora, portanto, deveria ter bastante conhecimento dela. Para nós, leitores do século XXI, os livros históricos são uma possível fonte de conhecimentos na busca de uma melhor compreensão das instituições sociais e jurídicas na Alemanha do século XVIII, como a do Gutsherr. O sistema político-social na Alemanha do século XVIII (e ainda do começo do século XIX) era caracterizado por traços de um feudalismo tardio (cf. WEHLER 1989:35). Embora o feudalismo, como sistema de organização social e política na Europa, tenha entrado em declínio a partir do século XIII, algumas das suas características perduraram em certos países, como é o caso da Alemanha. Uma dessas características era a organização social e política da vida rural, e a instituição do Gutsherr era, nesse contexto, emblemática. Em síntese: esses nobres alemães, sucessores dos vassalos de reis da Idade Média, eram grandes proprietários de terras, membros da aristocracia e tinham vários privilégios (sociais, políticos), oriundos ainda dos tempos feudais. Os camponeses que lavravam suas terras e que moravam nos seus territórios eram, de ponto de vista jurídico, seus súditos. Dentre os privilégios reservados a esses nobres estava o direito de exercer o poder policial e de administrar a justiça dentro da área de suas (em geral extensas) propriedades. Em suma, um Gutsherr era um chefe local, relativamente autônomo em relação ao poder central, e exercia seus privilégios dentro de um sistema político que lhe concedia essa autonomia (cf. WEIS 1978:11-16, WEHLER 1989:43).

Essa definição histórica do Gutsherr é coerente com a sua caracterização na Judenbuche. Mas ela acrescenta algo que não é perceptível a partir da mera leitura da obra: o caráter feudal contido no conceito do Gutsherr. É esse acréscimo que permite a identificação de algumas outras possibilidades de tradução dos termos Gutsherr e Gutsbesitz̧er. O feudalismo pode ser associado a termos portugueses como grande proprietário, (senhor) castelão ou senhor feudal. Um outro termo que pode ser associado a Gutsherr seria, por exemplo, o fidalgo, um indivíduo "que tem foros de nobreza, nobre" ou "que tem título de nobreza", como informa o Novo Dicionário Aurélio (AURÉLIO 1986).

A discussão acima fornece uma lista bastante extensa de traduções para as quatro denominações do personagem Gutsherr. O modelo aqui discutido, a tradução filológica, permite fazer algumas escolhas entre essas possibilidades: como a tradução filológica é voltada ao original e tenta preservar, na medida

6 Em termos da teoria do skopos, o mundo textual ("text-world") refere-se explicitamente à realidade da cultura-fonte ("source-culture reality") (cf. NORD 1997:87). Parece-me pertinente, portanto, analisar o personagem em termos históricos, não somente como uma invenção fictícia. 
do possível, os seus traços, acho justificado traduzir as quatro denominações, por meio de quatro termos correspondentes. Para a denominação Baron foi encontrada uma correspondente única e, a meu ver, bastante adequada: Barão. No caso de Herr von S. eu daria preferência ao termo mais genérico senhor - por corresponder mais ao igualmente genérico Herr - em vez do mais "ibérico" Dom. Proponho manter a preposição von, já que ela faz parte do nome e título do personagem e proporcionaria uma certa "estrangeirização", no sentido do termo tal como definido por VENUTI (1995:20), que, para mim, é uma das características de uma tradução retrospectiva ou voltada ao original (cf. VERMEER 1990:59), que é parte da definição da tradução filológica.

Já a tradução dos termos Gutsherr e Gutsbesitzerer é menos trivial, considerando a lista extensa de possibilidades encontradas. Com o modelo da tradução filológica como uma espécie de filtro, eu descartaria os termos proprietário e grande proprietário (pois me parecem genéricos demais, tanto em relação à propriedade rural quanto ao poder local), fidalgo (que denomina um nobre, mas sem a noção da propriedade de terras) e também senhor feudal, por acentuar talvez muito intensamente o aspecto do feudalismo, que já não era o padrão político central na época da trama, mas simplesmente um resquício de um regime passado.

Sobram três grupos de termos para a discussão: (1) coronel, como um termo da cultura brasileira, mas com certa proximidade semântica aos originais, (2) castelão, termo ligado à nobreza e feudalismo, e (3) fažendeiro, latifundiário e proprietário de terras, que transmitem a noção de propriedade rural, sem ter, no entanto, a noção do poder local que um Gutsherr exercia, bem como o aspecto de nobreza.

Seguindo a opção de tradução retrospectiva, proponho descartar o termo coronel, embora haja uma proximidade semântica relativamente grande com os termos Gutsherr e Gutsbesitzer. Mas apesar de várias semelhanças principalmente a da relativa autonomia política - o coronelismo brasileiro e o sistema feudal tardio europeu diferem significativamente: enquanto a autonomia dos coronéis era uma prática não sancionada formalmente pelo Estado, a autonomia dos senhores feudais fazia parte da ordem política dos Estados europeus. A tradução do Gutsherr dessa narrativa como coronel poderia desfigurar o personagem, transformando uma autoridade legítima (pelo menos 
naquela sociedade alemã do século XVIII) em uma pessoa autoritária. Além disso, falta ao termo coronel o aspecto da nobreza. ${ }^{7}$

Já o termo castelão combina melhor com a definição histórica do Gutsherr - um castelão sendo, na definição de Houaiss, um "senhor feudal que vivia em castelo e tinha o privilégio de administrar justiça em determinada área" (HouAiss 2002). O Gutsherr de Judenbuche vive, de fato, em um castelo. Mas, ao contrário do coronel, o termo castelão possivelmente não evoca muitas associações acerca de seu significado no Brasil, sendo um termo para uma instituição que nunca existiu por aqui. Além disso, por ser um termo técnico da época do feudalismo propriamente dito, é também, de um certo modo, anacrônico até para essa narrativa do século XVIII. Contudo, do ponto de vista de uma tradução retrospectiva, castelão parece mais adequado do que coronel.

Fazendeiro, latifundiário e proprietário de terras, finalmente, transmitem, como já mencionei, a noção de propriedade rural, mas falta-lhes a noção do poder local de um Gutsherr e também o aspecto de nobreza. Apesar disso, um leitor brasileiro poderia talvez conotar uma ligação, embora não "oficial", entre um dono da fazenda e poder político e jurídico, por ser familiarizado com o fenômeno do coronelismo, um aspecto bem conhecido na cultura brasileira. Um Gutsherr não era, porém, simplesmente um dono de propriedade rural; mas essa noção é importante na sua caracterização na Judenbuche. Portanto, e apesar de algumas diferenças, esses termos seriam, na minha opinião, possíveis candidatos para uma tradução filológica.

Dos quatro termos restantes - castelão, fazendeiro, latifundiário e proprietário de terras - nenhum corresponde completamente aos significados dos originais, tal como os defini aqui historicamente. Essa constatação não surpreende, tendo em vista a grande diferença entre o "mundo textual" da novela e a cultura-alvo, a cultura brasileira contemporânea; conceitos históricos de uma cultura raramente se traduzem facilmente para o presente de uma outra cultura. A questão aqui não é também definir qual dos termos seria o mais adequado, mas como proceder no caso de uma tradução filológica. A definição desse tipo de tradução recomenda traduzir "bastante literalmente" e remeter as informações consideradas necessárias para a compreensão para comentários e notas de rodapé. Uma solução seria, então, escolher um dos termos (ou dois, para diferenciar Gutsbesitzer e Gutsherr) e completar, em

7 Esta escolha afetaria também as opções de tradução do contexto do personagem do Gutsherr; por exemplo, o fato de ele morar num castelo: todo o contexto do Gutsherr teria de ser adaptado à vivência de um coronel. 
comentário ou nota de rodapé, a informação nele ausente para tornar compreensível a noção de Gutsherr.

A definição da tradução filológica recomenda também levar em conta outros aspectos do texto, como "peculiaridades lingüísticas". No caso de Gutsherr, há um detalhe interessante: o termo Gutsherr, tal como usado na Judenbuche, denominava um proprietário de terras nas regiões orientais da Alemanha, principalmente na Pomerânia Oriental, enquanto na região onde a autora morava, uma região ocidental da Alemanha, o termo usado para esse tipo de proprietários rurais era Grundherr; as duas denominações são também caracterizadas por diferentes perfis socio-econômicos e jurídicos (cf. WEIS 1978:14 s.). Seria então justificado perguntar-se por que Annette von DrosteHülshoff preferiu um termo pouco usado na sua região para denominar um personagem de uma narrativa da Vestfália. Para responder a essa questão, será necessário comparar os manuscritos da Judenbuche e consultar dicionários históricos e lingüísticos. ${ }^{8}$ Essa pesquisa poderia talvez mostrar ou indicar as razões da preferência pelo termo Gutsherr. De qualquer forma, os resultados de uma pesquisa sobre esse tipo de particularidades lingüísticas também deveriam fazer parte dos comentários de uma tradução filológica.

O modelo da tradução filológica parece-me útil para a preparação de comentários e anotações de uma tradução. A sua definição é vaga o suficiente para não ser normativa demais, e concreta o suficiente para estimular reflexões e sugerir caminhos para escolhas de tradução. No entanto, a definição desse modelo de tradução da teoria do skopos leva em conta somente aspectos funcionais de uma tradução, deixando de lado outros aspectos, como, por exemplo, questões de ideologia ou de estilo. Acredito, portanto, que a reflexão sobre um processo complexo, tal como o da tradução, necessite levar em conta mais do que a teoria do skopos sugere. Para a determinação de traduções de termos singulares dentro de um texto, a definição da tradução filológica provou-se, porém, bastante adequada.

8 Essa consulta ainda será feita no decorrer do projeto. 


\section{Segundo relato}

\section{A questão da ambientação na tradução para o Português do Brasil de Der Prinz und der Bottelknabe oder Erzähl mir vom Dow Jones.}

Por Cristiana Oliveira.

A tradução de uma obra estrangeira caracteriza-se como uma porta que se abre a uma nova cultura, a uma outra identidade. Toda história que se localiza em ambiente estrangeiro apresenta ao leitor uma série de elementos desconhecidos, tais como antropônimos, topônimos, títulos, medidas, moeda, alimentos, jogos, hábitos, entre outros. A tradução desses elementos, que ancoram a ação num ambiente estranho ao do leitor-receptor, coloca o tradutor diante de importantes escolhas.

O presente relato tem por objetivo apresentar alguns resultados parciais do meu projeto de Mestrado, que consiste na tradução anotada e comentada da obra Der Prinz und der Bottelknabe oder Erzähl mir vom Dow Jones, de Kirsten Boie, destinada ao público juvenil. Nele apresentarei alguns exemplos que revelam parte do processo de tomada de decisões no que respeita ao tratamento dispensado, na tradução, à questão da ambientação, procurando relacioná-los com algumas questões teóricas de fundo.

Cada escolha que se refere à localização da ação ultrapassa o simples processo de tradução mecânica, quer dizer, de troca de palavras, e exige reflexão e pesquisa, além da habilidade em se lidar com valores culturais diversos. Para VENUTI (1995), tal habilidade é revelada no grau de estrangeirização ou domesticação que o texto sofre ao ser traduzido. Segundo este teórico, uma tradução sempre comunica uma interpretação e o texto estrangeiro é suplementado com características peculiares à língua de chegada, sendo inevitavelmente domesticado.

AMORIM (2003) afirma que toda tradução recontextualiza a obra literária original reinscrevendo-a numa outra realidade. É através da geração de imagens, construídas a partir de uma rede de relações de sentido, que a outra realidade é percebida e compreendida. A domesticação ou recontextualização de textos estrangeiros têm como objetivo, portanto, tornálos acessíveis ao público alvo.

VENUTI (1995) lembra, porém, que por ser um ato de cruzamento de fronteiras, a tradução exerce um poder enorme na construção de representações de culturas estrangeiras e deve ser escrita com o maior respeito 
às diferenças lingüísticas e culturais. Sua crítica recai sobre as traduções em que a domesticação acaba por tratar assuntos estrangeiros como alegoria local e a criação de estereótipos étnicos. Para o teórico, a tradução não deve produzir o efeito ilusório de transparência, como se fosse algo não traduzido.

O equilíbrio entre a domesticação e a estrangeirização do texto pareceme o caminho para uma tradução que preserva a ancoragem do texto de partida (e, portanto, mantém a cor local da cultura de partida), ao mesmo tempo em que leva em devida conta o critério da legibilidade, fundamental para o tipo de texto do qual me ocupo neste trabalho. No caso da tradução de literatura infantil e juvenil, a tarefa de se atingir esse equilíbrio torna-se ainda mais séria, uma vez que se trata de um processo assimétrico. Cabe ao tradutor o conhecimento da faixa etária de seu público alvo e o emprego consciente e eficaz dos recursos lingüísticos, a fim de tornar seu texto acessível, familiar e prazeroso, tendo como pano de fundo a permanente preocupação com a construção da identidade estrangeira.

Passemos, então, ao caso concreto. O romance juvenil Der Prinz und der Bottelknabe oder Erzähl mir vom Dow Jones, escrito em 1997 pela autora alemã Kirsten Boie, é uma adaptação ou recriação da obra de Mark Twain, O príncipe e o mendigo. A história se desloca da cidade de Londres, Inglaterra, na segunda metade do século XVI, para Hamburgo, Alemanha, no final do século XX. Assim como no clássico de Twain, o livro conta a história de dois meninos, sósias, que nascem no mesmo dia e na mesma cidade, procedem, porém, de famílias e classes sociais bem diferentes. O menino rico é representado por Calvin Prinz e o pobre, por Kevin Bottel. Quando estão com aproximadamente quinze anos, encontram-se ao acaso e decidem trocar de papéis, a fim de "experimentarem" a vida um do outro.

Trata-se de uma narrativa acessível e agradável ao leitor adolescente. $\mathrm{O}$ uso de linguagem coloquial, as gírias, os jogos de palavras e os comentários irônicos são marcas distintivas desse texto e atribuem um toque cômico à história. Além disso, a obra caracteriza-se pela forte ancoragem do texto na cidade de Hamburgo, ambientação que confronta o leitor brasileiro com uma série de elementos que lhe são estranhos ou desconhecidos: topônimos, nomes de personagens, empresas, programas de televisão, marcas de produtos e lojas, além de costumes e comportamentos. Tais elementos transportam o leitor para dentro do universo alemão e permitem a construção de uma imagem da juventude na Alemanha. 
$\mathrm{Na}$ busca pelo equilíbrio entre as duas direções de tradução mencionadas anteriormente, a domesticação e a estrangeirização, o trabalho de tradução deste romance apóia-se em dois critérios principais: (1) a manutenção da ambientação e (2) a legibilidade.

Isso significa, de um lado, que o leitor tem à sua disposição o maior número possível de marcas culturais, que o ajudam na construção da identidade estrangeira; de outro, porém, sempre que essas marcas comprometem a legibilidade e, conseqüentemente, a compreensão da história, são realizados ajustes, cujo objetivo é recontextualizar diferenças lingüísticas e aspectos específicos da cultura alemã, tornado-os acessíveis ao leitor brasileiro.

Os elementos estrangeiros que foram "domesticados" nesse trabalho de tradução podem ser divididos em três categorias. São elas:

1. Elementos que não apresentam dificuldades de compreensão: nomes de personagens, empresas, localidades, entre outros, facilmente reconhecidos pelo leitor brasileiro e que exigem apenas pequenas modificações ou ajustes ortográficos.

a) “Da vorne ist die Elbe", sagte er." (p.61)

"O Elba está bem ali na frente", disse ele.

b) "Am Morgen in der Mathestunde hatte ich mich mit Tatjana gestritten...(p.19)"

"Pela manhã eu havia brigado com a Tatiana na aula de matemática..."

c) "Im dritten Stock hielt sie an und schloss eine Wohnungstür auf, auf der verschiedene Aufkleber für Kellogg's Cornflakes... warben." (p.71)

"Ela parou no terceiro andar e destrancou uma porta, na qual estavam colados vários adesivos de propaganda dos sucrilhos Kellogg's."

2. Elementos que apresentam dificuldades de compreensão, mas que podem ser substituídos:

a) "Sie hat eine Figur, an der Hennes und Mauritz aussieht wie Marc Cain oder Max Mara,... (p.21)"

"Ela tem um corpo, que faz $\underline{C \mathscr{E} A}$ parecer Armani ou Chanel,..." 
Nesta passagem o texto estrangeiro cita uma cadeia de lojas populares e duas lojas mais refinadas, respectivamente. Temos nessa passagem a presença do humor, da ironia, características marcantes da obra. A manutenção dos nomes das lojas comprometeria a compreensão da comparação e da respectiva ironia, uma vez que são desconhecidas no Brasil. As lojas escolhidas para a tradução atendem as características das lojas do original (popular/ refinadas) e obedecem ao critério da ambientação, pois são encontradas em toda a Alemanha.

b) “Welche Kartei?”, fragte Özden.

"Du bist ja nur neidisch!", schrie Zekriye. (p.20)

"Que book?", perguntou Salim.

"Você é que está com inveja!", gritou Yasmin.

Özden e Zekriye são personagens de origem turca, companheiros de classe do protagonista Kevin Bottel. Por serem desconhecidos no Brasil e possuírem uma grafia bastante diferente da língua portuguesa, estes antropônimos causariam bastante estranhamento e não permitiriam que o leitor brasileiro os relacionasse à comunidade turca, cuja presença na Alemanha é uma marca cultural que não pode ser ignorada. A adaptação desses nomes próprios, resultado de uma pesquisa de nomes turcos comumente encontrados no Brasil, objetiva, portanto, a legibilidade e a manutenção do traço cultural.

c) "Dass in diesem Augenblick die Mathemaus hereinkam...(p.21)"

"Bem nesse momento a Matemá entrou na classe..."

O personagem Kevin refere-se, de forma depreciativa, à professora de matemática como "Mathemaus". Essa forma de tratamento revela características do comportamento do personagem e colabora na construção da identidade da juventude alemã. $\mathrm{O}$ jogo de palavras possui dois aspectos a serem observados na tradução: o uso do animal "rato", como forma de depreciar a professora e a combinação de sons entre as palavras "Mathematik" e "Maus".

Devido à incompatibilidade na língua portuguesa das palavras "matemática" e "rato" no que diz respeito à sonoridade, é necessário que se faça uma escolha entre os dois aspectos acima citados. Após um trabalho de experimentação, optei por preservar a sonoridade, a fim de manter o humor 
do jogo de palavras. Desta forma, a palavra "rato" foi descartada na tradução, sendo, porém, compensada pela combinação sonora das palavras "matemática" e "má". Esta opção de tradução contempla ainda o aspecto de crítica à professora.

A fim de ilustrar o exercício de criatividade num trabalho de tradução dessa natureza, cito aqui outras possíveis soluções que surgiram durante o processo de experimentação: "Matemorte", "Matechática", "Matemonstra", "Mateanta" e "Má-temática".

3. Elementos que apresentam dificuldades de compreensão, mas que não podem ser substituídos:

a) "Manchmal schaltete Mama freitags abends Derrick ein oder den

Kommissar ,so Mutti- Filme eben... (p.78)"

"Às vezes mamãe ligava a televisão nas noites de sextafeira e assistia Derrick ou o Kommissar, essas séries policiais antigas, coisa de mãe..."

Temos, neste exemplo, os títulos de duas séries policiais alemãs dos anos 60 e 70, totalmente desconhecidas do público brasileiro. Neste caso, a substituição por similares torna-se mais difícil, uma vez que a escolha de uma série policial brasileira não obedeceria ao critério da ambientação. Uma possível solução para o problema seria a escolha de séries americanas como "Kojak", "Magnum" ou "Havaí 5-0", que respeitariam a questão da ambientação, uma vez que foram exibidas tanto no Brasil como na Alemanha. Por se tratarem, porém, de séries muito antigas, não seriam provavelmente reconhecidas pelos adolescentes de hoje (público alvo deste romance), o que acabaria por ferir o critério da legibilidade. A substituição de um elemento estranho por outro, que se revelaria também estranho, não se justifica e invalida a domesticação, que tem como objetivo tornar o texto acessível ao leitor. Sendo assim, a opção da tradução foi a manutenção dos títulos originais, acompanhados de uma expansão, isto é, uma explicação no corpo do texto.

b) "Warum sollte ich in dieser Wohnung aushalten, an deren Wänden die BRAVO-Poster noch am ehesten minimalen ästhetischen Ansprüchen genügten?" (p.75) 
"Por que é que eu deveria agüentar ficar nesse apartamento, cujas paredes cobertas com pôsteres de revistas de adolescentes não preenchiam os requisitos mínimos de estética?”

BRAVO é uma revista alemã bastante popular entre os adolescentes. Assim como no exemplo anterior, não é possível a substituição por uma revista similar, sendo, portanto, utilizado mais uma vez o recurso da expansão.

Como vemos, a tradução de uma obra estrangeira está permeada de aspectos importantes, que cobram do tradutor uma postura crítica e análise cuidadosa. Inscrever o leitor numa realidade estrangeira permite a construção da imagem de uma outra cultura, tratando-se, portanto de um trabalho delicado e de responsabilidade.

O romance comentado neste artigo apresenta, como já foi dito, uma linguagem jovem e possui passagens cômicas e irônicas, características que atraem e "prendem" o leitor adolescente. A principal diretriz deste trabalho reside na busca do equilíbrio entre a construção da cultura estrangeira e a manutenção das características motivadoras da leitura, tais como a legibilidade e o humor. Não se trata apenas de recontar a história, mas também de transportar o leitor para dentro do universo juvenil alemão, fornecendo instrumentos para que ele compreenda e aprecie este universo. Para tanto, o trabalho de tradução exige um processo de mediação entre as duas culturas: a de partida e a de chegada, que envolve interpretação e criatividade.

Este processo de mediação é destacado por ARROJO (1993):

(...) o original não existe como objeto estável, guardião implacável das intenções originais de seu autor.... O leitor somente poderá estabelecer uma relação com o texto..., que será sempre mediada por um processo de interpretação, um processo muito mais "criativo" do que "conservador", muito mais "produtor" do que "protetor" (p.19).

Cabe ressaltar que os ajustes aqui sugeridos foram discutidos com a autora do romance, por via eletrônica, e se encontram ainda em fase de análise. De todo modo, a reflexão sobre uma estratégia de tradução para esse tipo recorrente de problema foi a única forma encontrada para atribuir unidade e coerência ao processo de tomada de decisões. 


\section{Terceiro relato}

\section{A linguagem de Freud em Zur Auffassung der Aphasien - Eine kritische Studie e sua tradução para o Português do Brasil.}

Por Emiliano Rossi.

Uma pesquisa de mestrado em tradução requer, desde o início, o estabelecimento de critérios norteadores dessa empreitada. À definição e justificativa da escolha do texto deve seguir uma contextualização do mesmo e um levantamento de suas características constitutivas. A partir desse alicerce, definem-se o objetivo e o propósito da tradução, a partir do que são eleitos os critérios que nortearão as escolhas que acompanham o processo de tradução propriamente dita.

A obra que constitui o escopo de minha pesquisa, Zur Auffassung der Aphasien - Eine kritische Studie, é tida como a primeira publicação freudiana e data de 1891. Pré-psicanalítico, esse livro médico, inscrito no debate neurológico sobre a anatomo-fisiologia cerebral, tem um caráter marcadamente científico. Nele, SIGMUND FREUD procura expor as principais conclusões a que os mais eminentes teóricos chegaram naquela época acerca da compreensão das afasias e, a partir de sua filiação filosófico-científica, empreender uma crítica a essas posições, à época hegemônicas, bem como dar sua colaboração à concepção de funcionamento do aparelho de linguagem.

No texto em questão, Freud não apenas emprega amplamente a nominalização - recurso que começa a se tornar proeminente na língua alemã a partir da época do iluminismo (cf. PolENZ, 1985) - como também desenvolve suas idéias apoiado numa estrutura argumentativa própria do tipo de texto técnico-científico. A tais características somam-se, então, o diacronismo da linguagem - considerado, é claro, a partir da perspectiva da tradução a ser realizada num momento que dista mais de 100 anos do momento em que o texto original foi escrito -, as características mesmas da linguagem freudiana deste texto, situada no âmbito do registro formal, seu estilo peculiar e, não menos importante, a ancoragem desse texto inaugural na fortuna crítica do século XIX. Estes são, em síntese, alguns dos aspectos que deverão ser tidos em consideração para orientar as escolhas desta tradução.

Seguindo um modelo de tradução retrospectiva (cf. VERMEER, 1990 e SNELL-HORNBY, 2006), nossa tradução do texto freudiano visa à recuperação do original com o menor grau de descaracterização possível, trazendo-o aos 
falantes da língua portuguesa do Brasil do século XXI com a tentativa de manutenção da linguagem, do estilo e do ritmo próprios à época em que foi escrito e ao autor que o escreveu. Nesse sentido, faz-se necessário o acréscimo de notas e comentários explicativos ao longo da tradução, que explicitem alguns recursos empregados pelo tradutor, bem como as estratégias utilizadas e dificuldades encontradas.

Passemos, então, à exemplificação de algumas dificuldades encontradas no processo de tradução, bem como das estratégias utilizadas para a solução dos mesmos, sustentadas pelas reflexões sucintamente esboçadas acima.

Consideremos o parágrafo de abertura do livro em questão:

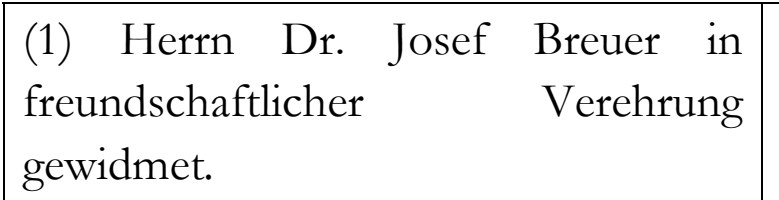

„(2) Wenn ich, ohne über neue eigene Beobachtungen $\mathrm{zu}$ verfügen, ein Thema $\mathrm{zu}$ behandeln versuche, an welches bereits die besten Köpfe der deutschen und fremdländischen Neuropathologie, wie Wernicke, Kussmaul, Lichtheim und Grashey, Hughlings Jackson, Bastian und Ross, Charcot u. a., ihre Kraft gewendet haben, so tue ich wohl am besten, sogleich die wenigen Punkte des Problems zu bezeichnen, in deren Erörterung ich einen Fortschritt einzuleiten hoffe. (3) Ich werde mich also bemühen zu zeigen, da $\beta$ in der Lehre von der Aphasie, wie sie durch das Zusammenwirken der eben genannten Forscher geworden ist, zwei Annahmen enthalten sind, welche man besser durch andere ersetzen kann oder welche zum mindesten vor diesen anderen Annahmen nichts Entscheidendes voraus haben. (4) Die erste dieser
(1) Dedicado ao Senhor Josef Breuer, em amigável honorificência.

(2) Se eu, sem dispor de novas observações próprias, procuro abordar um tema ao qual já voltaram suas forças as melhores cabeças da neuropatologia alemã e estrangeira, como Wernicke, Kussmaul, Lichtheim, e Grashey, Hughlings Jackson, Bastian e Ross, Charcot, entre outros, então, o melhor mesmo que tenho a fazer é indicar, desde logo, os poucos pontos do problema em cuja discussão espero introduzir um avanço. (3) Esforçar-me-ei, portanto, em demonstrar que na doutrina das afasias, na forma que ela adquiriu através do esforço coletivo dos pesquisadores supracitados, estão contidas duas suposições, que se poderiam substituir afortunadamente por outras, ou que, no mínimo, diante destas novas suposições nada têm de decisivo. (4) A primeira dessas suposições tem como conteúdo a diferenciação entre as afasias provocadas por destruição dos centros 
\begin{tabular}{ll|l|}
\hline Annahmen hat zum Inhalte die & daquelas provocadas por destruição das \\
Unterscheidung von Aphasie durch & vias de condução ela encontra-se em \\
Zerstörung der Zentren von solcher & quase todos os autores que \\
durch Zerstörung der Leitungsbahnen; sie & escreveram sobre as afasias. (5) A \\
findet sich bei nahezu allen Autoren, & segunda suposição diz respeito à \\
welche über Aphasie geschrieben & relação recíproca entre cada um dos \\
haben. (5) Die zweite Annahme & centros, supostamente ligados às \\
betrifft das gegenseitige Verhältnis & funções de linguagem, e encontra-se \\
der einzelnen für & principalmente em Wernicke e \\
Sprachfunktionen angenommenen & naqueles pesquisadores que aceitaram \\
Zentren und findet sich hauptsächlich & e desenvolveram a linha de raciocínio \\
bei Wernicke und jenen Forschern, & desse último autor. \\
welche Wernickes Gedankengang & \\
angenommen und weiterentwickelt & \\
haben. &
\end{tabular}

A primeira marca que ilustra o modelo retrospectivo de tradução encontra-se logo na primeira sentença desse excerto (indicada com o algarismo 1 entre parêntesis no quadro acima), que corresponde à dedicatória que Freud faz de seu livro a seu amigo JOSEF BREUER. O leitor brasileiro contemporâneo, ao qual a tradução se destina, percebe de forma eminente o anacronismo da linguagem freudiana em relação aos hábitos lingüísticos de nosso tempo. A escolha para a tradução desse período poderia ser feita no sentido de amenizar o estranhamento do leitor, caminho que não estaria em sintonia com o modelo retrospectivo, em que a primazia é dada à recuperação mais aguda do original, e não à familiaridade das escolhas ao universo lingüístico do leitor do século XXI. Trata-se aqui, também, de uma convenção que ilustra o primeiro exemplo de marca característica do tipo de texto científico, uma convenção que demonstra a diacronia da linguagem utilizada, seu registro formal e o estilo de FREUD.

O segundo comentário explicativo retoma outra questão estilística. $\mathrm{Na}$ segunda frase do texto freudiano destacam-se dois aspectos: 1 - o ponto de partida da crítica freudiana, consubstanciada em forma de livro, sua contextualização e a nomeação dos autores que servirão de referência ao trabalho que se inicia; e 2 - o contraste das estruturas frásticas características das línguas alemã e portuguesa e, além disso, o estilo da escrita freudiana, que se vale constantemente de períodos complexos, hipotaxes e parataxes. 
Questões de caráter morfossintático ensejam nosso terceiro comentário. Atendo-nos, nesse momento, à terceira frase de nossa citação, vemo-nos confrontados com a primeira ocorrência de uma mesóclise, forma gramatical atualmente em desuso, excetuando-se o âmbito jurídico. Aí talvez se encontre o exemplo mais claro de escolhas lexicais que derivam da proposta de tradução retrospectiva. A escolha da mesóclise para a tradução desse trecho advém da tentativa de recuperar o registro formal utilizado por Freud em sua escrita.

Nas duas últimas frases restantes, respectivamente de número quatro e cinco, surgem pela primeira vez expressões técnicas que constituem, em grande parte, uma das características idiossincráticas desse texto freudiano. As três expressões técnicas: "destruição dos centros", "destruição das vias de condução" e "centros [de linguagem]", representam os primeiros exemplos de um vernáculo médico que está abundantemente presente ao longo de todo o texto. Essa peculiaridade do texto científico deverá ser tratada de forma a respeitar a nomenclatura médica e poderá ensejar a elaboração de um pequeno léxico contrastivo para a padronização da tradução de expressões recorrentes.

Por fim, a estratégia de recuperar retrospectivamente (VERMEER 1990,

SNELL-HORNBY 2006) o texto freudiano não deve ser entendida no sentido de se chegar a um texto em português, cuja formulação e constituição venha a provocar um estranhamento no leitor brasileiro, a ponto de lhe obstruir ou dificultar a compreensão. Tal efeito colateral, por assim dizer, de uma tradução retrospectiva não levaria em devida conta a questão da legibilidade e seria indesejável nesse caso, sobretudo por se tratar de um texto de natureza científica, que prima pela divulgação de idéias. Contudo, a proposta sucintamente descrita aqui sublinha os traços de uma diretriz de tradução que visa à recuperação não apenas do que o autor tinha a dizer - o que daria primazia apenas ao conteúdo -, mas também ao modo como ele o fez. Nesse sentido, o que se busca é um "caminho do meio", que recupera tanto a marca de uma escrita, quanto se esforça por vencer, através de notas e comentários, aspectos ligados à recepção do texto traduzido, cuja compreensão foi dificultada pelo lapso de tempo que separa os processos de produção do original, de um lado, e da tradução, de outro. 


\section{Conclusão}

Os relatos aqui apresentados tiveram por objetivo fazer um recorte sincrônico num tipo de trabalho de grau envolvendo a tradução - a tradução comentada e anotada -, com o propósito de mostrar em que medida esses trabalhos representam, ao mesmo tempo, continuidade e ruptura em relação a uma tradição. Tendo por base fundamentalmente NoRD (1997), NowINSKA dá ênfase ao anacronismo do léxico num texto literário do séc. XIX e às conseqüências, para a tradução, da ancoragem cultural de termos e conceitos associados à História. Por sua vez, OliveIRA amplia essas considerações para outras categorias de palavras (topônimos, antropônimos, sintagmas nominais complexos etc.), buscando em VENUTI (1995) e AMORIM (2003) apoio para discutir questões polêmicas como a da adaptação e criatividade em tradução. Rossi, por fim, acrescenta à discussão um recorte num nível mais abrangente da análise lingüística - o da estilística e dos gêneros textuais - para, com base principalmente em VERMEER (1990) e SNELL-HORNBY (2006), nortear sua adoção do conceito de tradução retrospectiva.

Ainda que, em essência, o propósito de tais trabalhos continue sendo a apresentação, ao leitor brasileiro, de obra inédita de autor da literatura alemã ou de área específica do saber, os relatos aqui apresentados redefinem os contornos desses trabalhos que, diferentemente das primeiras produções desse gênero realizadas na Universidade de São Paulo nas décadas de 1960 e 1970, tentam incorporar avanços obtidos pelos Estudos da Tradução no Brasil e no exterior nas últimas quatro décadas e ganham articulações e interfaces com estudos realizados em áreas correlatas.

Considerando-se, ainda, a grande diversidade de vertentes dos Estudos da Tradução, estabelecidas nas últimas décadas, a direção dessas pesquisas por mais que elas possam diferir em seus objetos de investigação - continua sendo aquela que vai da prática para a teoria: é a partir da reiteração de problemas e questões concernentes à tradução que se procede ao recorte necessário no suporte teórico que dará sustentação à reflexão. E a diretriz de tradução, elaborada num trabalho de ir e vir entre teoria e prática, é o que concretiza e dá unidade a esse tipo de trabalho, ao mesmo tempo em que lhes garante a transparência na escolha das opções de tradução e a relativização do vínculo com uma vertente teórica, características indispensáveis à produção científica em tradução. 


\section{Referências bibliográficas}

Amorim, Lauro Maia. Tradução e Adaptação: entre a identidade e a diferença, os limites da transgressão. Dissertação de Mestrado. São José do Rio Preto, IBILCE-UNESP, 2003.

Arrojo, Rosemary. Tradução, Desconstrução e Psicanálise. Rio de Janeiro, Imago, 1993.

AzenHA JR. João. “O Curso de Tradução na Universidade de São Paulo: algumas reflexões sobre seu momento fundador.” In: AZENHA JR., JOÃO (org.) - Os Caminhos da Institucionalização dos Estudos da Tradução no Brasil. Trabalhos apresentados por membros do Grupo de Tradução da ANPOLL (Associação Nacional de Pós-Graduação e Pesquisa em Letras e Lingüistica) por ocasião do XXI Encontro Nacional dessa Associação, realizado na PUC-SP em julho de 2006. Belo Horizonte, UFMG, www.letras.ufmg.br/gttrad, 2007.

BOIE, Kirsten. Der Prinz und der Bottelknabe, oder Erzähl mir vom Dow Jones. Hamburg, Verlag Friedrich Oetinger, 1997.

Droste-HülhofF, Annette von. Die Judenbuche. Ein Sittengemälde aus dem gebirgichten Westfalen. Mit einem Kommentar von Christian Begemann. Frankfurt am Main, Suhrkamp, 1999.

FREUD, Sigmund. Zur auffassung der Aphasien - Eine kritische Studie. Herausgegeben von Paul Vogel, bearbeitet von Ingeborg MeyerPalmedo, Einleitung von Wolfgang Leuschner. Frankfurt am Main: Fischer Taschenbuch Verlag, zweite unveränderte Auflage, 2001.

Nord, Christiane. Translating as a Purposeful Activity. Functionalist Approaches Explained. Manchester, St. Jerome, 1997.

Polenz, Peter Von. Deutsche Satzsemantik: Grundbegriffe des Zwischen-den-Zeilen Lesens. Berlin / New York, de Gruyter, 1985.

SNELL-HornBy, Mary. The Turns of Translation Studies: New paradigms or shifting viewpoints? Amsterdam / Philadelphia, John Benjamin's Publishing Company, 2006.

TyTLER, Graeme. "The Presentation of Herr von S. in Die Judenbuche". In: The German Quarterly 73.4/2000, 337-350.

VenuTI, Lawrence. The Translator's Invisibility: A bistory of translation. London; New York: Routledge, 1995. 
VERMEER, Hans J. "Retro- oder prospektiv? Bibelübersetzung als Beispiel". in: Der Deutschunterricht 42.1/1990, 59-64.

WEHLER, Hans-Ulrich. Deutsche Gesellschaftsgeschichte, Bd. 1: Vom Feudalismus des Alten Reiches bis zur defensiven Modernisierung der Reformära: 1700-1815. München, Beck, 1989.

WeIS, Eberhard (Hg.). Propyläen Geschichte Europas. Bd. 4: Der Durchbruch des Bürgertums: 1776 - 1847. Frankfurt am Main, Propyläen, 1978.

\section{Outras obras de referência consultadas:}

[AurÉlio] Novo Dicionário Aurélio da Lingua Portuguesa, 2a ed., Rio de Janeiro: Nova Fronteira, 1986.

DudEN - Deutsches Universalwörterbuch, 6. Aufl., Mannheim: Duden, 2006 [versão eletrônica].

[Houniss] Dicionário Honaiss da Lingua Portuguesa, Rio de Janeiro: Objetiva, 2002.

LANGENSCHEIDTS Taschenwörterbuch Portugiesisch, Berlin \& München: Langenscheidt, 2001.

[PORTO] Dicionário de alemão - português, Porto, Porto Editora, 1986.

Catálogo de Teses e Dissertações 1942-1997. Comissão de Pós-Graduação da Faculdade de Filosofia, Letras e Ciências Humanas da Universidade de São Paulo. São Paulo, Xamã VM Editora e Gráfica Ltda., 1998. 